\title{
CORRECTION
}

Check for updates

Cite this: J. Mater. Chem. A, 2019, 7, 27186

DOI: $10.1039 / c 9 t a 90281 c$

www.rsc.org/MaterialsA

\section{Correction: Brønsted acid mediated covalent organic framework membranes for efficient molecular separation}

Hongjian Wang, ${ }^{\text {ab }}$ Long Chen, (D) ${ }^{c}$ Hao Yang, ${ }^{a b}$ Meidi Wang, ${ }^{\text {ab }}$ Leixin Yang, $^{\text {ab }}$ Haiyan Du, ${ }^{d}$ Chenliang Cao, ${ }^{a b}$ Yanxiong Ren, ${ }^{a b}$ Yingzhen $\mathrm{Wu}^{\text {ab }}$ Fusheng Pan (D) *ab and Zhongyi Jiang (iD) *ab

Correction for 'Brønsted acid mediated covalent organic framework membranes for efficient molecular separation' by Hongjian Wang et al., J. Mater. Chem. A, 2019, 7, 20317-20324.

The authors regret an error in the omission of the Acknowledgements section from the published article: the National Natural Science Foundation of China funding number "21409583" should in fact read "21490583".

The Royal Society of Chemistry apologises for these errors and any consequent inconvenience to authors and readers. 